\title{
OS HIDROCONFLITOS E A HIDRODIPLOMACIA NA GESTÃO DAS BACIAS HIDROGRÁFICAS INTERNACIONAIS. $O$ caso Ibérico.
}

\author{
Carmen Ferreira ${ }^{(a)}$ \\ (a) Departamento de Geografia/Faculdade de Letras, Universidade do Porto - Portugal, dra.carmenferreira@gmail.com
}

\section{Mesa Redonda 1: Bacias Hidrográficas e Recursos Hídricos: Análise, Planejamento e Gestão}

\begin{abstract}
Resumo
As águas transfronteiriças estendem a interdependência hidrológica para além das fronteiras nacionais, ligando consumidores de diferentes países dentro de um sistema partilhado. Gerir essa interdependência constitui um grande desafio ambiental, político e diplomático para os Estados que partilham bacias hidrográficas, no sentido de garantir a sustentabilidade e equidade desse recurso natural vital a todas as partes. A água pode alimentar conflitos generalizados mas também poderá funcionar como ponte para futuras relações de cooperação. Ao longo da história os governos de Portugal e Espanha têm sabido encontrar soluções inovadoras e cooperantes para resolver as tensões, que existem, relacionadas com a gestão das bacias hidrográficas transfronteiriças, mesmo em climas políticos complicados. O mesmo se almeja para um futuro cujos cenários das alterações climáticas traçados para Portugal exigirão uma maior acuidade na gestão deste recurso natural.
\end{abstract}

Palavras chave: Hidroconflitos; Hidrodiplomacia; Bacias Hidrográficas Internacionais; Caso Ibérico.

\section{Hidroconflitos e Hidrodiplomacia}

Com todas as suas potencialidades, a água tornou-se um recurso natural geoestratégico e de grande importância política (STEGNER, 1992). A história de conflitos de utilização da água entre ribeirinhos já vem de longa data e regista-se até nas fábulas mais antigas. Já Platão, no seu livro As Leis, propunha que aquele que houvesse corrompido ou desviado a água fosse obrigado ao pagamento de uma indemnização pelo prejuízo e a limpar o que havia sujado (JAEGER, 2002). Interessante verificar que os primeiros conceitos, institutos e instrumentos próprios do direito do ambiente que surge no fim do séc. XX, mais concretamente nos anos 80, tais como o "princípio do poluidor-pagador", o conceito de "dano ecológico", a instituição da "reposição da situação anterior à infração", afinal já tinham surgido na mente do grande filósofo Platão, no seu livro As Leis, pelo menos no ano 348/7 a.C. Existem hoje no mundo aproximadamente 200 sistemas fluviais que passam por vários países e as possibilidades de conflito na gestão destes recursos são bastante elevadas já que, em determinadas partes do mundo, muitos desses sistemas são explorados até à exaustão. É da natureza das coisas que as perturbações a montante perturbem os utilizadores a jusante. Não conseguindo dar respostas às necessidades dos países que ficam a jusante, geram-se, não só, tensões internacionais, como também tensões internas entre setores sociais e 
económicos em disputa pela água (TEIXEIRA, 2005). As razões das tensões entre países com recursos hídricos partilhados estão, entre outros fatores, relacionadas com as elevadas densidades populacionais e a maior demanda de água por expansão da urbanização e expansão da agroindústria, com as relações pouco amistosas entre as partes, com a implementação de grandes projetos hídricos e com as limitações de acordos/tratados sobre água doce. Atualmente, o consumo da água multiplicou-se, calculando-se que, por volta do ano de 2025, cerca de 3,5 biliões de pessoas possam estar a sofrer com a escassez de água (TEIXEIRA, 2005). Neste sentido, a água tornou-se uma questão de segurança e de defesa do EstadoNação devendo constar do planeamento estratégico de todos os países, em especial daqueles considerados "fontes hídricas" (TEIXEIRA, 2005). A maior ameaça à segurança de um país relativamente a este recurso natural é a segurança humana, decorrente da escassez de água, que poderá originar ameaças à segurança e defesa nacionais. A gestão de bacias hidrográficas internacionais constitui um desafio ambiental, diplomático e político no sentido de proporcionar um acesso equitativo e com qualidade, deste recurso natural vital, a todas as partes. As questões hídricas na política externa constituem uma nova forma de poder - um exemplo de soft power nas relações entre Estados. É já um tema prioritário na agenda internacional. É a grande oportunidade diplomática que poderá permitir salvar milhões de vidas, promover interesses de segurança nacional e proteger o meio ambiente. A água é, de facto, um recurso naturalmente estratégico para a política interna e externa de qualquer país do mundo.

\section{As águas ibéricas e as relações luso-espanholas}

Relativamente às principais bacias hidrográficas que o nosso país possui, Portugal é, nitidamente, um país de jusante. Para além dos recursos hídricos que têm as suas nascentes em território português e no nosso país desaguam, as bacias transfronteiriças do rio Minho, Lima, Douro, Tejo e Guadiana, contribuem para que a posição de Portugal seja confortável relativamente à disponibilidade de água por habitante/ano (CORREIA, 2000). Segundo Correia (2000, p. 30, 31) a situação de Espanha é muito mais crítica e muito mais próxima de uma situação de stress hídrico do que Portugal. No entanto, enquanto que Espanha apresenta um total controlo sobre os seus recursos hídricos, Portugal, que possui cerca de dois terços (64\%) do seu território em bacias hidrográficas internacionais e 50\% dos seus recursos hídricos são transfronteiriços, encontra-se numa posição de maior vulnerabilidade a tudo o que acontece aos recursos hídricos do país de montante. No que respeita aos recursos hídricos, Portugal é um país "dependente" (fig. 1). Relativamente às águas ibéricas, importa recordar que os acordos bilaterais entre os dois países têm vindo a ser celebrados desde o século XIX, quando a 29 de Setembro de 1864 se define a fronteira entre Portugal e Espanha desde a foz do rio Minho até à confluência do rio Caima com o rio Guadiana. 

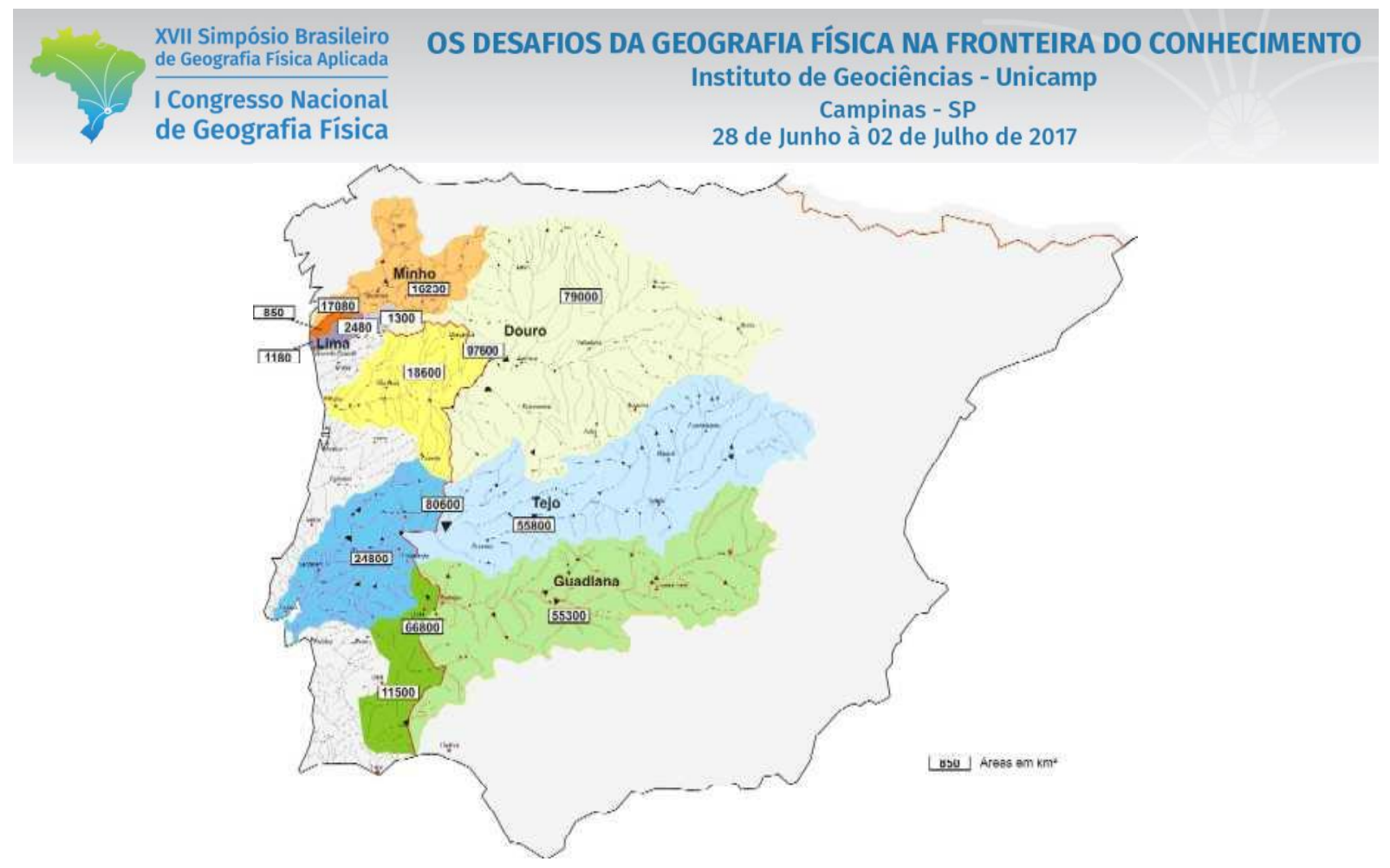

Repartição das Áreas das Bacias Hidrográficas Luso-Espanholas

\begin{tabular}{|c|c|c|c|c|c|}
\hline $\begin{array}{c}\text { Bacia } \\
\text { Hidrográfica }\end{array}$ & $\begin{array}{c}\text { Área Total } \\
\left(\mathrm{Km}^{2}\right)\end{array}$ & $\begin{array}{l}\text { Portuga } \\
\text { Área }\left(\mathrm{Km}^{2}\right)\end{array}$ & $\%$ & $\begin{array}{l}\text { Espanha } \\
\text { Área }\left(\mathrm{Km}^{2}\right)\end{array}$ & $\%$ \\
\hline Minho & 17080 & 850 & 5 & 16230 & 95 \\
\hline Lima & 2480 & 1180 & 48 & 1300 & 52 \\
\hline Douro & 97600 & 18600 & 19 & 79000 & 81 \\
\hline Tejo & 80600 & 24800 & 31 & 55800 & 69 \\
\hline Guadiana & 66800 & 11500 & 17 & 55300 & 83 \\
\hline TOTAL & 264560 & 56930 & 22 & 207630 & 78 \\
\hline
\end{tabular}

Fonte: Plano Nacional da Água (1994), p.2 (3-II)

Figura 1 - Bacias Hidrográficas Luso-Espanholas e repartição das áreas das bacias hidrográficas por Portugal e Espanha.

De todos os convénios estabelecidos, a Convenção de Albufeira (CA) - assinada em Albufeira a 30 de Novembro de 1998, foi aquela que nos parece ter dado um maior avanço nas relações bilaterais PortugalEspanha em termos de recursos hídricos, instituindo dois órgãos de cooperação: a Conferência das Partes (CoP), de carácter político e destinada a estabelecer acordos sobre questões não solucionadas na Comissão para a Aplicação e Desenvolvimento da Convenção (CADC), segundo órgão instituído, de carácter técnico, tanto na sua composição como nas suas atribuições. A esta Comissão compete, não apenas funções de carácter processual destinadas à cooperação, mas também a coordenação de medidas e ações para a proteção e aproveitamento sustentável das bacias hidrográficas Luso-Espanholas (ROSADO, 2011, p. 129). Por ser a mais recente convenção que se encontra em vigor entre os dois Estados, será objeto de uma particular atenção neste trabalho, como exemplo do grande desafio que foi feito à diplomacia de ambas as partes para se chegar a consensos. Assim, e porque a mesma surge em consequência do Plano 
Hidrológico Nacional Espanhol (PHNE), estabelecido em 1993, muitas tensões e controvérsias foram vivenciadas pelos dois Estados, até se estabelecer a Convenção de Albufeira. O período de negociações foi longo, os pontos de discórdia eram vários e a política dos transvases do PHNE foi a que teve um maior protagonismo pelos impactes que poderia originar em Portugal, um país de jusante. Acrescente-se, ainda, que a experiência em termos de planeamento dos recursos hídricos eram bem diferentes entre as partes. Enquanto que a Espanha tinha já uma longa prática deste tipo de planeamento, em Portugal, apenas em 1994, se introduziu no quadro jurídico nacional esse requisito - Decreto-Lei no 45/94 de 22 de Fevereiro. Este diploma jurídico regula, não somente o processo de planeamento de recursos hídricos mas também a elaboração e aprovação do Plano Nacional da Água (PNA), e dos 15 Planos de Bacias Hidrográficas. As dificuldades encontradas pelos responsáveis da hidrodiplomacia portuguesa e espanhola foram sendo solucionadas, com custo para cada uma das partes, com avanços e retrocessos, até finalmente se chegar ao acordo da Convenção de Albufeira. Devemos também assinalar que, nessa altura, as orientações que estavam em discussão para a preparação da Diretiva Quadro da Água (DQA) da União Europeia (UE), que iria estabelecer um quadro de ação comunitária no domínio da política da água, eram favoráveis às posições portuguesas. As disponibilidades de água em Portugal são condicionadas pelo clima e pelo regime de utilização em Espanha das águas das bacias hidrográficas partilhadas. Tem-se verificado uma diminuição das disponibilidades de água afluente de Espanha, quer por efeito do aumento do seu uso, quer pela implementação de transvases. As utilizações da água em Espanha interferem com a salubridade dos aquíferos a jusante, muitas vezes em território português, dificultando as ações de fiscalização e remediação. É o caso do risco de descargas com níveis de radiação de centrais nucleares junto ao Douro internacional e ao Tejo internacional. A presença de centrais nucleares em Espanha merece-nos uma grande preocupação, sobretudo a central de Almaraz, que dista apenas $100 \mathrm{Km}$ da fronteira portuguesa e se situa na bacia hidrográfica internacional do rio Tejo. A central nuclear de Almaraz possui um sistema de refrigeração em circuito aberto, utilizando as águas do rio Tejo. O risco de Portugal ser afetado por águas radioativas prevalece, colocando em causa a segurança das populações ribeirinhas. A central nuclear de Almaraz tem sido muito contestada por o seu tempo de vida ter terminado em Junho de 2010 e por o governo espanhol ter decidido mantê-la em funcionamento por mais 10 anos, até 2020. E é precisamente esta central nuclear de Almaraz a protagonista de mais um conflito que surge em janeiro de 2017 entre Portugal e Espanha, a propósito da decisão tomada, unilateralmente, por Espanha, em construir um armazém de resíduos nucleares na central de Almaraz. Os impactos ambientais que tal decisão pode causar a Portugal são muitos e diversos. O governo português considera não ter sido cumprido o princípio da legalidade, uma vez que Espanha não fez uma avaliação dos impactos transfronteiriços daquele tipo de armazenagem, violando, por isso, uma diretiva comunitária. Apesar de toda a diplomacia utilizada no 
acompanhamento deste diferendo, Portugal afirma que ativará todos os procedimentos para que a legislação comunitária em matéria de ambiente seja cumprida. Estamos perante um caso de hidroconflito verbal ibérico, o mais atual, que se relaciona com a preservação da qualidade das águas de uma bacia hidrográfica internacional, para o país de jusante. A segurança humana exige, cada vez mais, que os recursos hídricos transfronteiriços sejam geridos de forma cooperativa.

\section{Notas conclusivas}

Se durante anos não houve diferenças significativas no desenvolvimento económico entre Espanha e Portugal, atualmente essas diferenças existem e têm consequências políticas. Os interesses de Espanha relativamente à gestão dos recursos hídricos podem ser e muitas vezes são, contraditórios aos de Portugal pois beneficiam de um fator favorável e de enorme importância: os rios correm de Espanha para Portugal e não em sentido inverso (CUNHA, 1998). Já em 1998, Veiga da Cunha (p. 45) referia que "a liberdade de movimentos que Portugal tem consentido a Espanha permitiu que, ao longo de (...) décadas, se criassem nefastas situações de facto consumado que nos colocam, sem dúvida, perante um futuro que se afigura recheado de dificuldades (...)" e, questionando-se se poderão existir situações de conflitos violentos, entre Portugal e Espanha, envolvendo a gestão de recursos hídricos transfronteiriços, o autor (p. 43) não parece muito categórico quando afirma "Não, necessariamente. Isto é, depende, como é o caso em muitas outras situações". O mesmo autor refere que a gestão dos recursos hídricos é um excelente campo para avaliar o funcionamento da democracia e, acrescentamos nós, de uma efetiva hidrodiplomacia, no sentido de se desenvolverem mecanismos de cooperação capazes de enfrentar as situações de maior insegurança ambiental e de prevenir a existência de conflitos.

\section{Bibliografia}

CORREIA, F. N. Introduction to the problems of shared watercourses and transboundary issues. In: VLACHOS, E.; CORREIA, F. N. (Org.). Shared Water Systems and Transboundary Issues with special emphasis on Iberian Peninsula. Lisbon: Luso-American Foundation Ed., 2000. p. 23-41.

CUNHA, L. V. Segurança Ambiental e Gestão dos Recursos Hídricos. Nação e Defesa, Lisboa, 1998, 86, $2^{\circ}$ série, p. 27-50.

JAEGER, W. Paidéia: los ideales de la cultura griega. Cidade do México: Fondo de Cultura Económica, 2002.

PORTUGAL. Diário da República 44/94 SÉRIE I-A de 22 de fevereiro de 1994. Lex: Decreto-Lei no 45/94.

ROSADO, S. A. Rios que nos separam, águas que nos unem. Análise jurídica dos Convénios Luso-Espanhóis sobre águas internacionais. Valladolid: Fundación Lex Nova, 2011.

STEGNER, W. Beyond the Hundredth Meridian: John Wesley Powell and the Second Opening of the West. New York: Penguin Books, 1992.

TEIXEIRA, F. Por uma geopolítica da água: conheça o mapa dos conflitos. 2005. Disponível em: http://ivairr.sites.uol.com.br/geopoliticadaagua.htm. Acesso em: 17 dez. 2010. 